\title{
Interactive comment on "Mapping soil slaking index and assessing the impact of management in a mixed agricultural landscape" by Edward J. Jones et al.
}

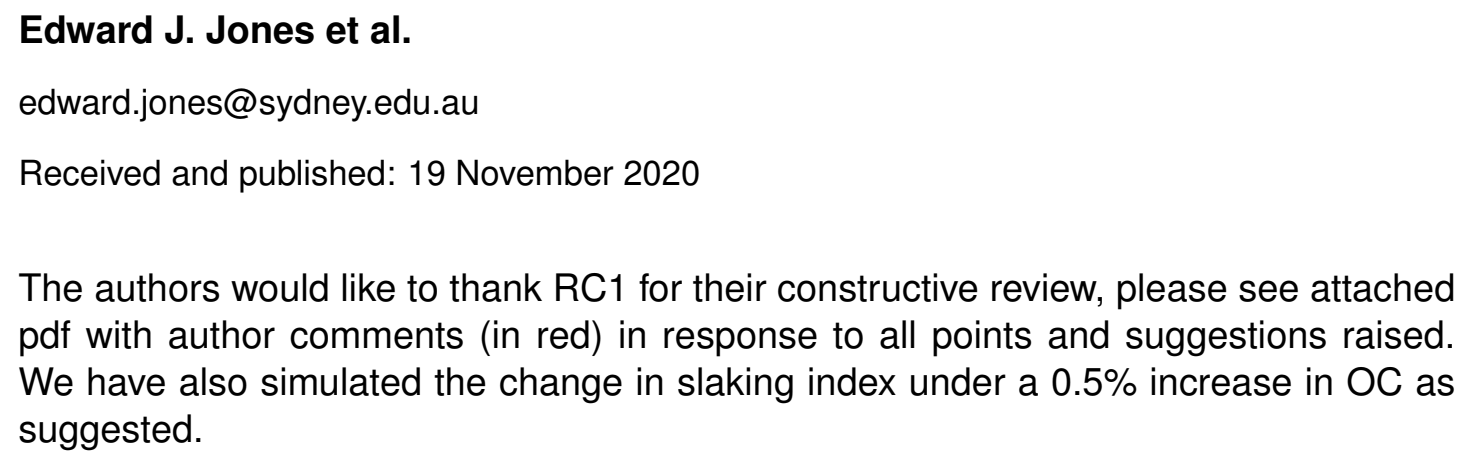

The authors would like to thank RC1 for their constructive review, please see attached pdf with author comments (in red) in response to all points and suggestions raised. We have also simulated the change in slaking index under a $0.5 \%$ increase in OC as suggested.

Please also note the supplement to this comment:

https://soil.copernicus.org/preprints/soil-2020-29/soil-2020-29-AC1-supplement.pdf 